\title{
BLDC Motor Drive Simulation for Electric Bicycle
}

\author{
M. A. A. Younis ${ }^{1}$, Abir A. Al-Moqbali ${ }^{2}$, Omirah H. Al-Quraini ${ }^{3}$, Sheikha A. Al-Fazari ${ }^{4}$, Sumaiya S. Al-Mamari ${ }^{5}$ \\ ECE Department, Sohar University, Sultanate of Oman ${ }^{1,2,3,4,5}$
}

\begin{abstract}
This paper presents design of Brushless DC motor (BLDC) driver for electrical. The drive system includes converter to produce the required voltage for BLDC. Hall Effect sensor is needed to decide on the position of the permanent magnet to match it with the right BLDC coil. The Hall Effect sensors are displaced by $120^{\circ}$ which will produce voltage signals on the output displaces by the same phase shift. The generation of converter switching signals depends on the signals supplied by Hall Effect sensor for synchronization. Simulink software is used to verify the design validity by running several tests on the system operation. The simulation result is shown to validity verification.
\end{abstract}

Keywords: Brushless DC motor; Three phase inverter; inverter switching, Simulink.

\section{INTRODUCTION}

The advantages of Permanent Magnet Brushless DC (BLDC) Motors over brush DC Motor are Higher efficiency and reliability, Lower acoustic noise, Smaller and lighter, Greater dynamic response, Better speed versus torque characteristics, Higher speed range, and Longer life. Therefor industry encouraged to replace the brush DC motor by BLDC in many applications such as automotive, aerospace, medical, automated industrial equipment and instrumentation. Due to the mentioned advantages, BLDC found to be the most suitable motor for electrical bicycles. There are different types of bicycle used by people all over the world, like a paddle bicycle which need a lot of energy to move the bicycle. Motorized bicycle usesfuel which makes harmful environmental pollution, and electric bicycle which use electrical motor supplied. Electric bicycle operate more efficiently by brushless DC motor (BLDC) [1] [2] [3].

The rotor of a BLDC motor is a permanent magnet other as shown in Figure 1. The stator has a coil arranged and displaced by 1200 .

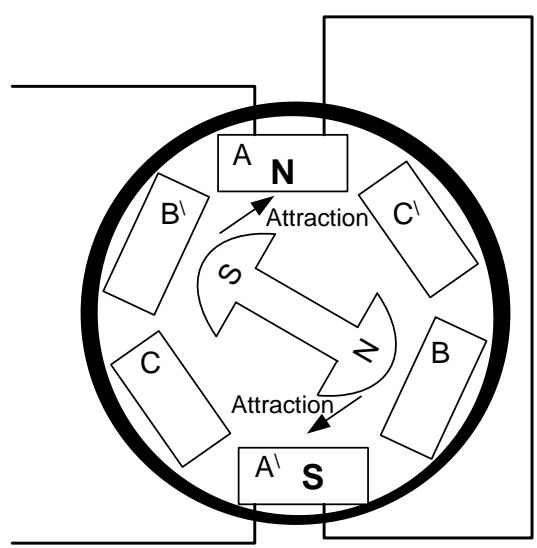

Figure 1.BLDC motor principle of operation
The rotor has 3 coils, named A, B and C. By applying DC power to the coil, the coil will energize and become an electromagnet. The operation of a BLDC is based on the simple force interaction between the permanent magnet and the electromagnet coil [5].

When coil A is energized, the opposite poles of the rotor and stator are attracted to each. As a result the rotor poles move near to the energized stator. The voltage signal applied to coil A will move to the following coil which will be energized to attract the rotor opposite pole. The voltage signal will circulate to all the coils to complete full cycle [5] [6]. The six switches are produces output voltage suitable for BLDC motor drive is shown in Figure 2 . The switches are switched ON and OFF in the sequence shown in Figure 3. Switches $\mathrm{S} 1$ and $\mathrm{S} 2$ should be complement to each other (S1 ON, S2 OFF), so do switch pairs $(\mathrm{S} 3, \mathrm{~S} 4)$ and $(\mathrm{S} 5, \mathrm{~S} 6)$.

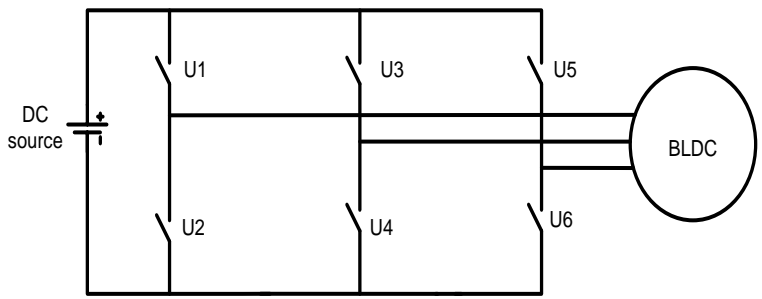

Figure 2: Three phase inverter

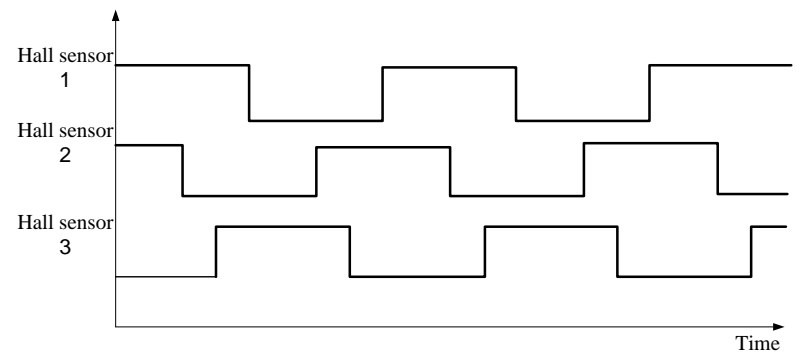

Figure 3: Hall Effect for Six Steps Inverter 
Vol. 5, Issue 1, January 2017

Switch pairs must not close or open at the same time to avoid a short circuit across the source [4]. Brush less DC motor is driven by six step interval with the help of hall position sensor.

Figure 4 shows the line to line output voltages $\mathrm{V}_{\mathrm{AB}}, \mathrm{V}_{\mathrm{BC}}$ and $\mathrm{V}_{\mathrm{CA}}$ are $+\mathrm{V}_{\mathrm{DC}},-\mathrm{V}_{\mathrm{DC}}$ or 0 . For a star connected load of inverter, it is also called as six step inverter due to six steps in the output waveforms for the line to neutral voltage resulting from the six switching transitions per period [6] [7]. In this paper brushless DC motor (BLDC) drive is used for electric bicycle application. The BLDC motor operates with the help of whole effect sensor which detect the permanent magnet pole and help to energize the right coil to establish the attraction force.

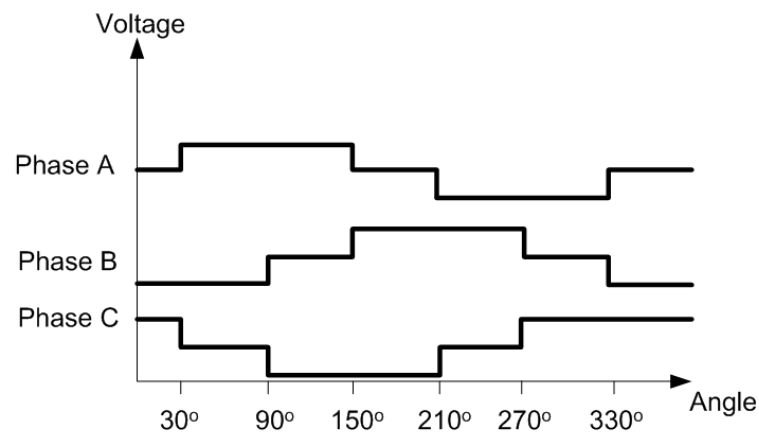

Figure 4. Line to Line Output Voltage

\section{SYSTEM BLOCK DIAGRAM}

The block diagram of the system is shown in Figure 5. Inverter is the main part in the system which converts the DC voltage taken from the battery to a voltage suitable to drive BLDC. The output voltage of inverter is connected to brushless DC motor (BLDC). The position of BLDC motor is controlled by hall sensor which is used for proximity switching, positioning, speed detection, and current sensing applications. The sensor operates as an analogue transducer, directly returning a voltage when magnetic field exists. When the magnetic field location is known, the right coil can be determined [8]

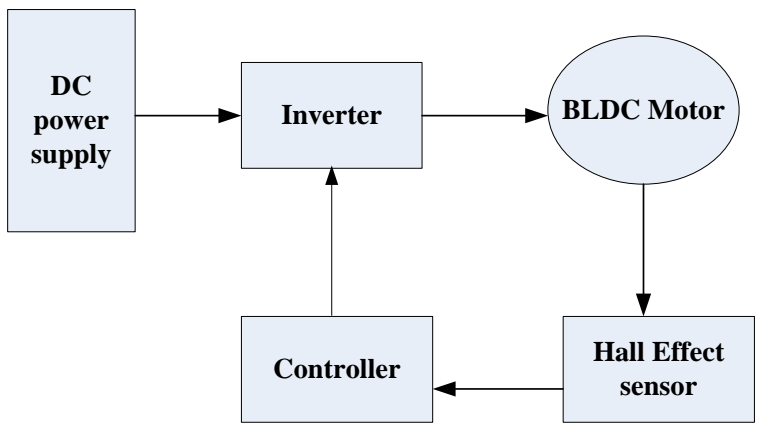

Figure 5: Block diagram of the system

Whenever the rotor magnetic poles pass near the Hall sensors they give a high or low signal indicating the $\mathrm{N}$ or $\mathrm{S}$ pole is passing near the sensors. Based on the combination of these three Hall sensor signals, the exact sequence of commutation can be determined. Each Hall Effect sensor detect the south pole of a magnet and sends a signal to the controller input [8]. The speed of the motor can be controlled if the voltage across the motor is changed, which can be achieved easily by varying the duty cycle of the PWM signal used to control the six switches of the three phase bridge.

\section{SYSTEM DESIGNAN AND SIMULATION}

The system shown in Figure 6 is simulated using MATLAB/ SIMULINK. Its include permanent magnet synchronous machine which have the same principle of BLDC operation. The parameter of BLDC are given in Table 1 It consists of four input ports and five output ports. The output port consists of hall signals, speed, and torque, current and back-EMF (Eb) signals.

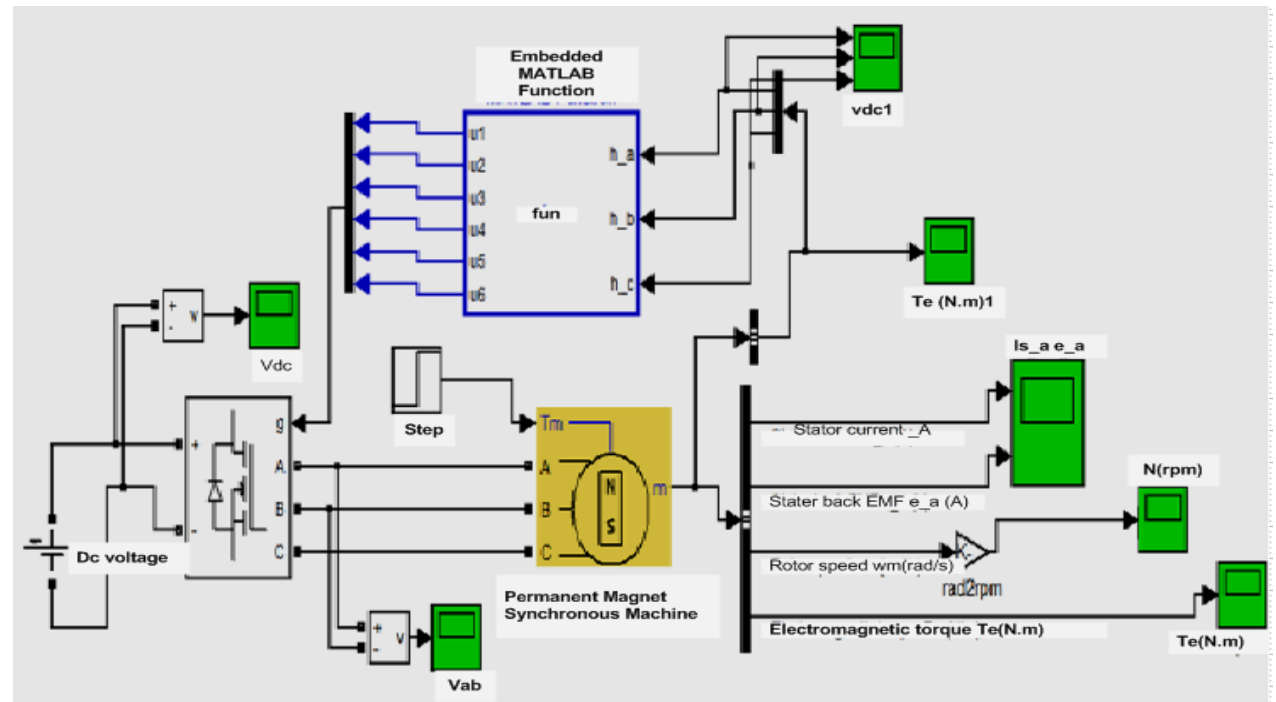

Figure 6: Overall model of BLDC motor 
International Journal of Innovative Research in Electrical, Electronics, Instrumentation and Control Engineering

ISO 3297:2007 Certified

Vol. 5, Issue 1, January 2017

Table1: Motor parameters

\begin{tabular}{|l|c|}
\hline \multicolumn{1}{|c|}{ Motor Parameters } & Values \\
\hline Input Voltage, $\mathrm{V}_{\mathrm{Dc}}$ & $36 \mathrm{~V}$ \\
\hline Stator phase resistance ( rs ) & $2.8750 \Omega$ \\
\hline Stator phase inductance (Ls) & $8.5 \mathrm{mH}$ \\
\hline Load Torque & $1 \mathrm{~N}-\mathrm{m}$ \\
\hline
\end{tabular}

\section{Three Phase Inverter}

The three phase inverter which the main part of BLDC system is shown in Figure 7. It's used to produce the DC power suitable for the BLDC motor operation. The three phase inverter consists of six switches arranged on three legs. The switching signal sequence of inverter switches are generated using EMBEDDED MATLAB function block, which used to write MATLAB code, embedded in SIMULINK model. The generated code is shown in Figure 8 and it's written to satisfy the condition given in Table 2 . The sequence of motor operation depends on six states, in each state signal is generated depending on the production of the hall sensor signal. Hall Effect signals of the motor are produced according to the rotor position. Table 3 shows the truth table of Hall Signals and the back-EMFs. Hall sensor signals are produced According to a particular rotor position for the respective hall signal its corres ponding back-EMF is decoded.

Table 2: Switching sequence of BLDC motor

\begin{tabular}{|c|c|c|c|c|}
\hline State & $\begin{array}{c}\text { Switches } \\
\text { Closed }\end{array}$ & $\begin{array}{c}\text { Phase } \\
\text { A }\end{array}$ & $\begin{array}{c}\text { Phase } \\
\text { B }\end{array}$ & $\begin{array}{c}\text { Phase } \\
\text { C }\end{array}$ \\
\hline 0 & S1\& S6 & + & - & off \\
\hline 1 & S1\& S2 & + & Off & - \\
\hline 2 & S2\& S3 & Off & + & - \\
\hline 3 & S3\& S4 & - & + & Off \\
\hline 4 & S4\& S5 & - & Off & + \\
\hline 5 & S5\& S6 & off & - & + \\
\hline
\end{tabular}

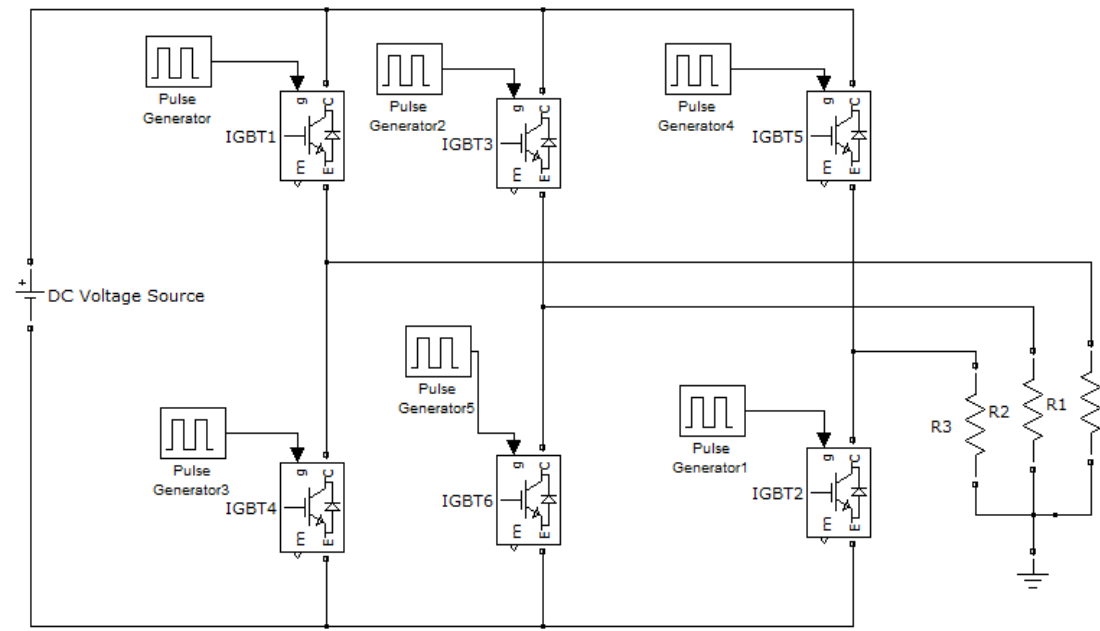

Figure 7: Three phase of full wave inverte

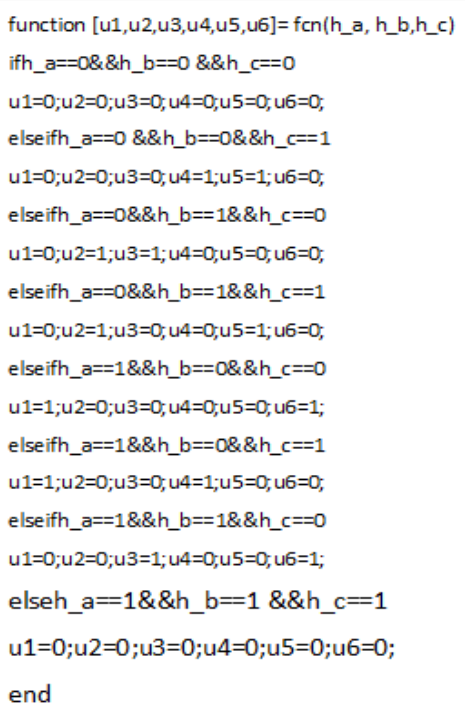

Figure 8: MATLAB switching code 
International Journal of Innovative Research in Electrical, Electronics, Instrumentation and Control Engineering

ISO 3297:2007 Certified

Vol. 5, Issue 1, January 2017

In implementation of the truth given in table 2, at any emf_b and emf_c) the input of inverters gate U1to U6, instant two phases are conducting, one phase is +ve and each of the them controls one switch. For example if the other phase is $-\mathrm{ve}$. Hence its corresponding switches will hall sensor is $(+1,-1,0)$ the input of switch U1 to U6 are be triggered as per the given truth table 2 . The input of six $(0,0,0,0,1,1$ and 0$)$.

switch depended on hall sensor of BLDC motor (emf_a,

Table 2: Hall decoder truth table

\begin{tabular}{|c|c|c|c|c|c|c|c|c|c|c|c|}
\hline Hall a & Hall $\mathrm{b}$ & Hall c & emf_a & emf_b & emf_c & U6 & U5 & U4 & U3 & U2 & U1 \\
\hline 0 & 0 & 0 & 0 & 0 & 0 & 0 & 0 & 0 & 0 & 0 & 0 \\
\hline 0 & 0 & 1 & 0 & -1 & 1 & 0 & 1 & 1 & 0 & 0 & 0 \\
\hline 0 & 1 & 0 & -1 & 1 & 0 & 0 & 0 & 0 & 1 & 1 & 0 \\
\hline 0 & 1 & 1 & -1 & 0 & 1 & 0 & 1 & 0 & 0 & 1 & 0 \\
\hline 1 & 0 & 0 & 1 & 0 & -1 & 1 & 0 & 0 & 0 & 0 & 1 \\
\hline 1 & 0 & 1 & 1 & -1 & 0 & 0 & 0 & 1 & 0 & 0 & 1 \\
\hline 1 & 1 & 0 & 0 & 1 & -1 & 1 & 0 & 0 & 1 & 0 & 0 \\
\hline 1 & 1 & 1 & 0 & 0 & 0 & 0 & 0 & 0 & 0 & 0 & 0 \\
\hline
\end{tabular}

\section{RESULTS AND DISCUSSION}

Figure 9 shows the six pulses generated to switch the six switches of the inverter

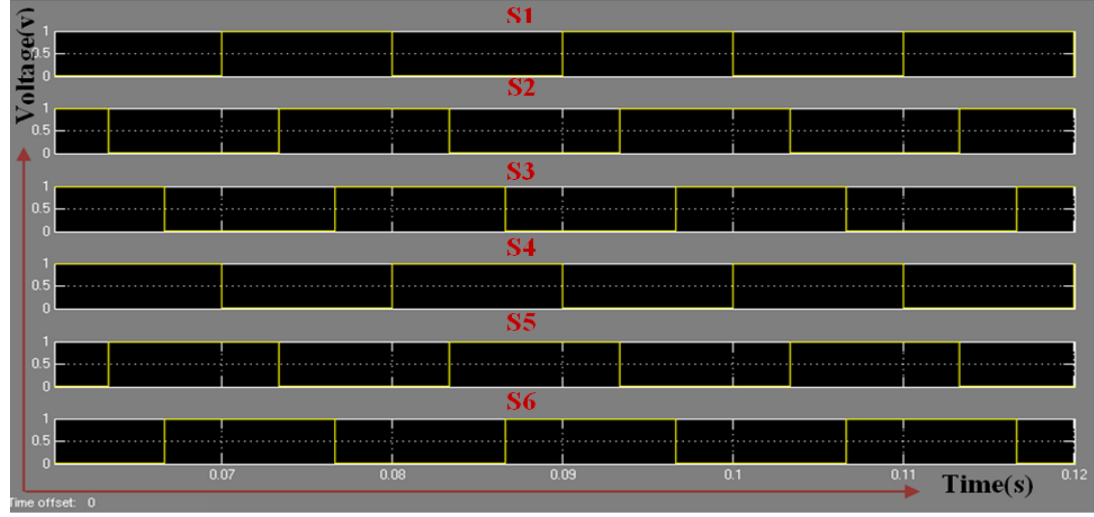

Figure 9: The input pulses for six switches

Figure 10 shows the output of three phase inverter at $150 \mathrm{~V}$ which connected to BLDC motor.

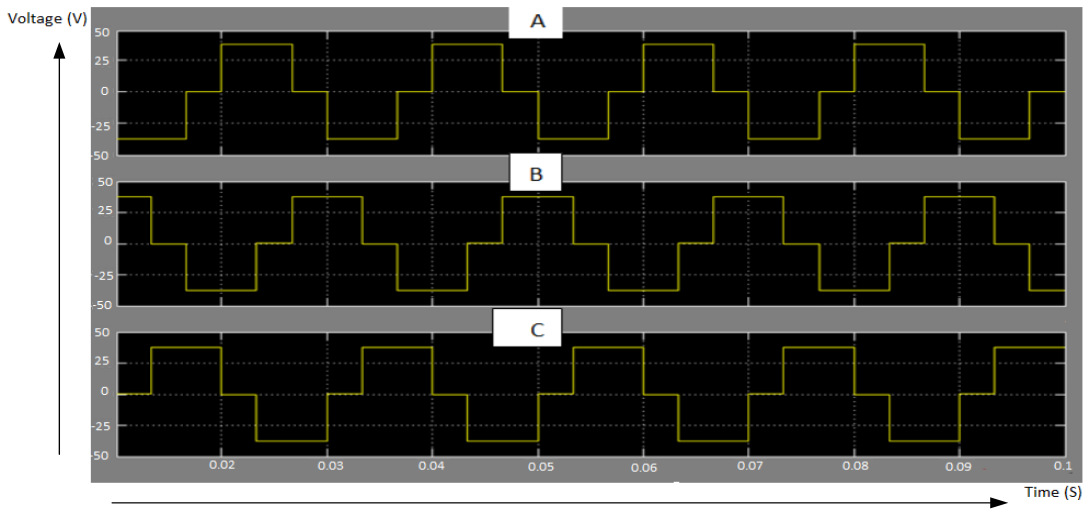

Figure 10: The output of three phase inverter

The motor torque curve is shown in Figure 11. The speed of $634.6 \mathrm{rpm}$. The torque is decreased to 0.08227 maximum torque is at time of $0.1 \mathrm{~s}$, then it decrease to N.m and the trapezoidal back-EMF settles at $17.44 \mathrm{~V}$ as steady state value. Figure 12 depicts the variation of speed shown in Figure 13.

with respect to time. The motor reaches the steady state 
IJIREEICE

International Journal of Innovative Research in Electrical, Electronics, Instrumentation and Control Engineering

ISO 3297:2007 Certified

Vol. 5, Issue 1, January 2017

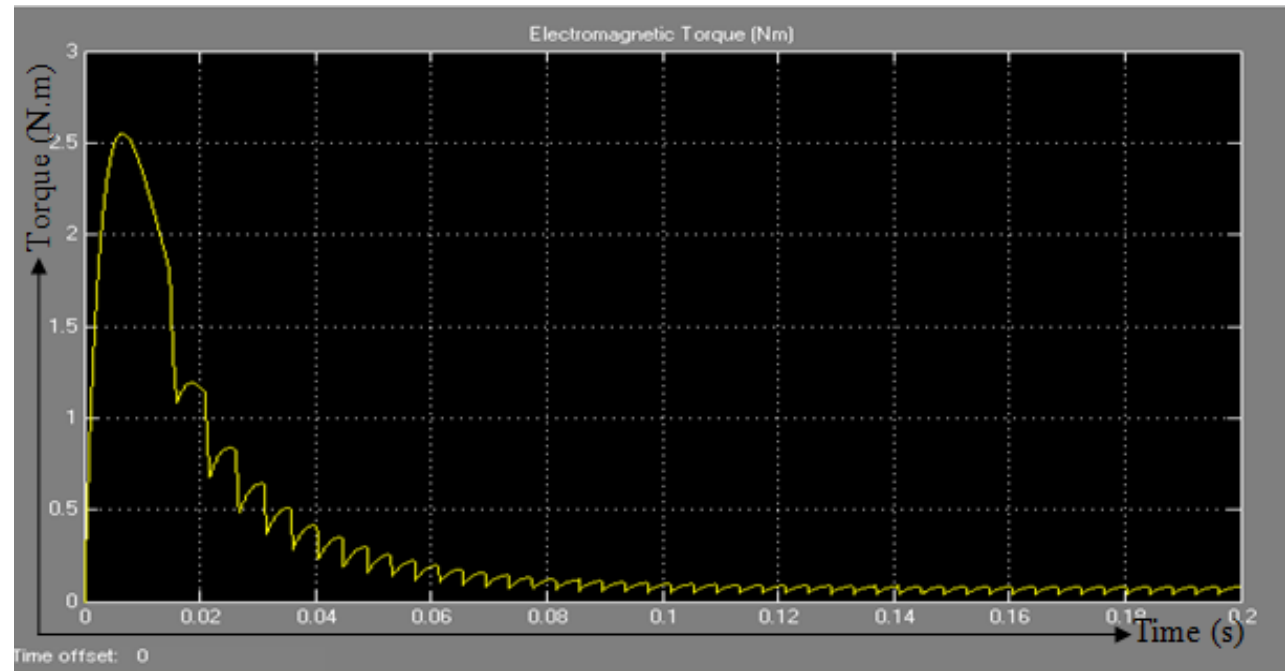

Figure 11: Torque (N.m)

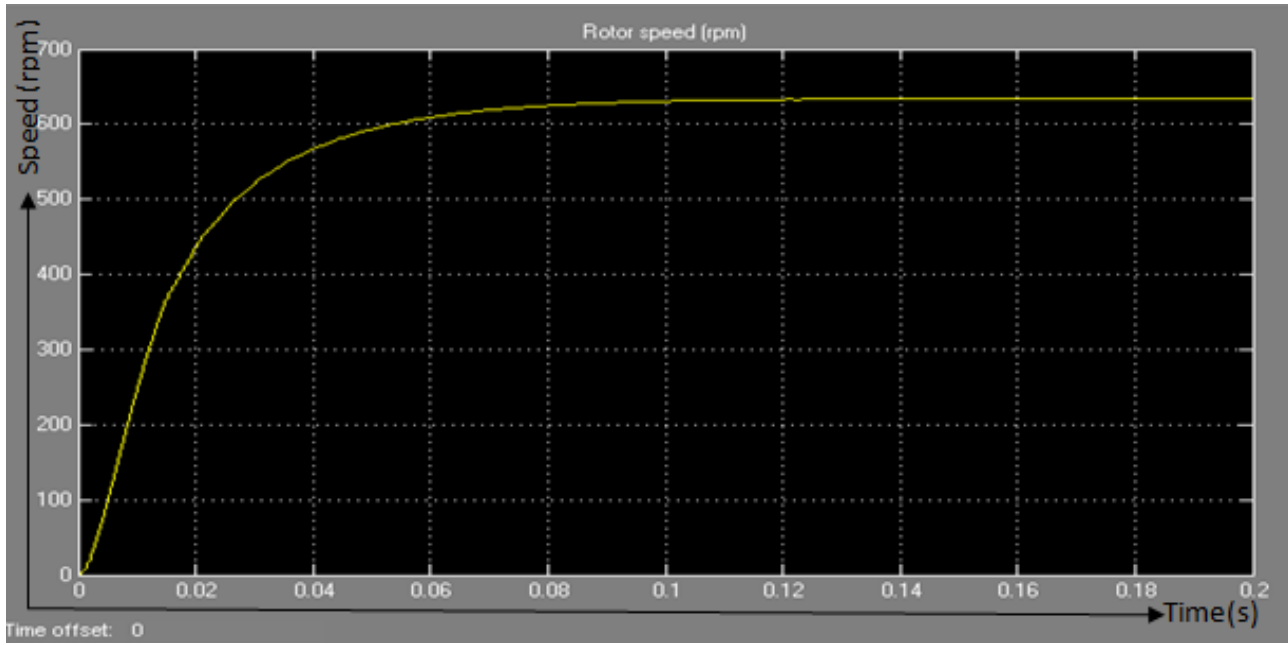

Figure 12: Speed (rpm)

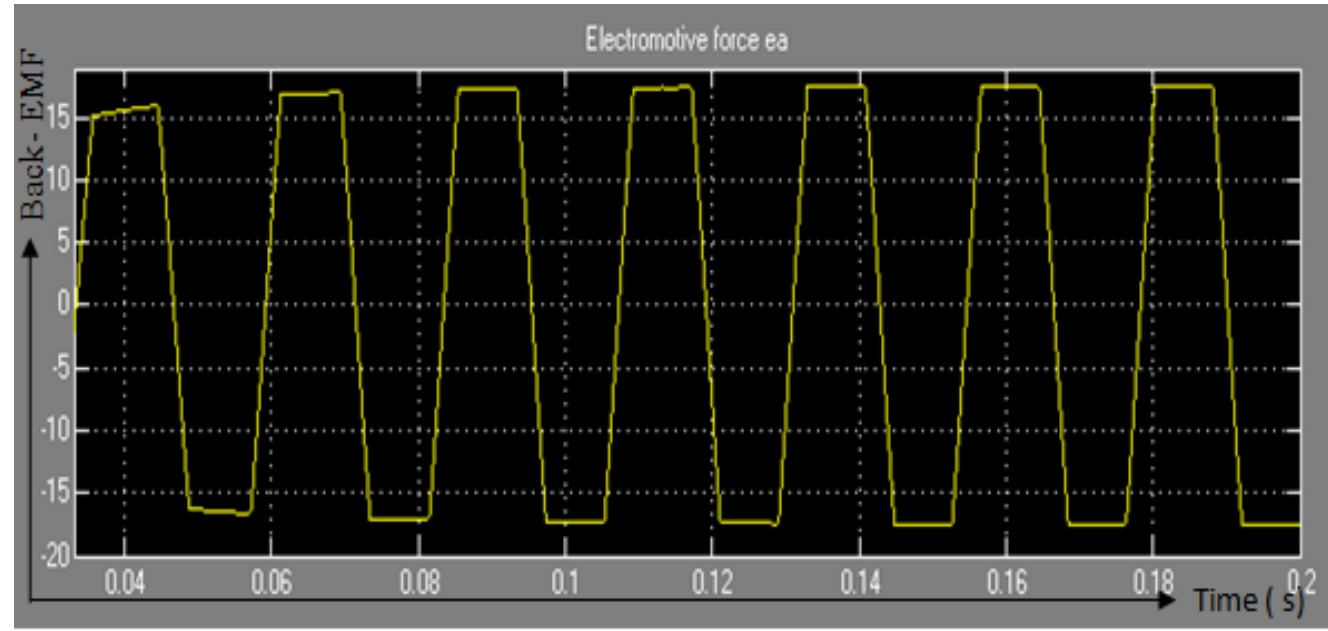

Figure 13: Back-EMF

Figure 14 shows the relationship between speed, input the speed start to decrease from $650 \mathrm{rpm}$ to $400 \mathrm{rpm}$. torque and output torque. When there is no load the speed However, the output torque start to increase until it is maximum, input torque is minimize and the output reached steady state of $1 \mathrm{~N} . \mathrm{m}$. torque is sharply decreased. When there is a load of $1 \mathrm{~N} . \mathrm{m}$, 
IJIREEICE

International Journal of Innovative Research in

Electrical, Electronics, Instrumentation and Control Engineering

ISO 3297:2007 Certified

Vol. 5, Issue 1, January 2017

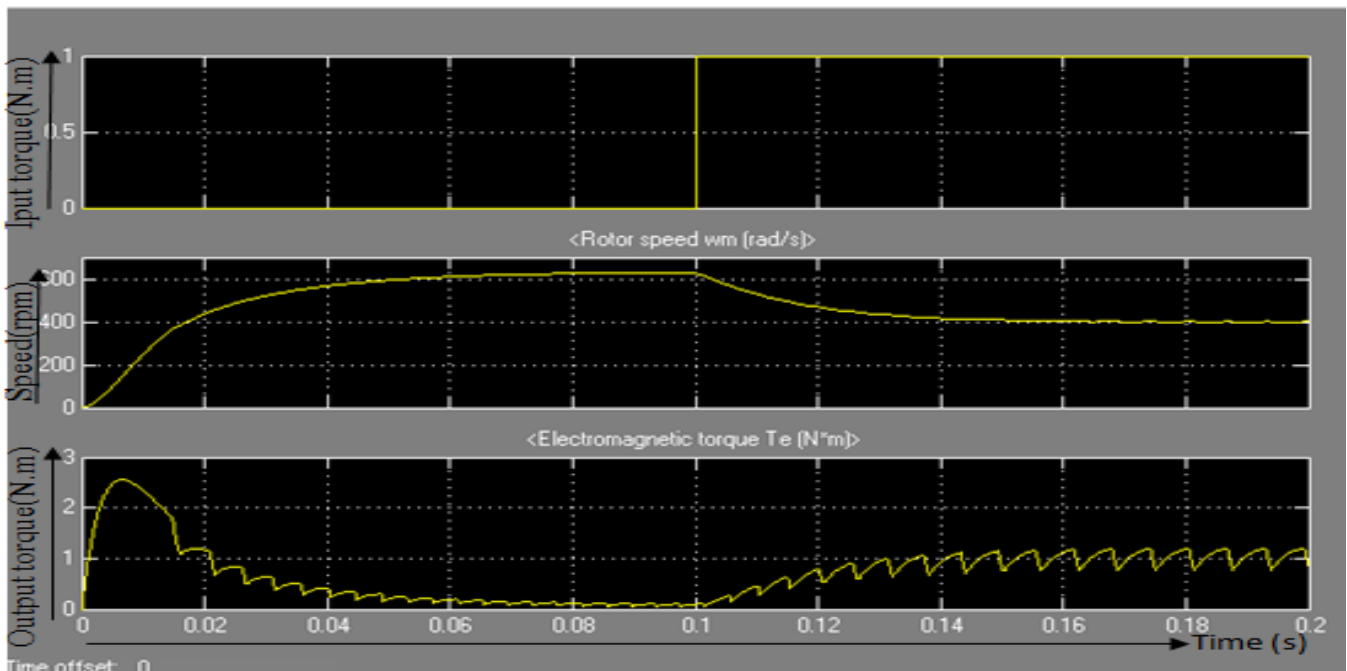

Figure 14: Relationship between Speed, Input Torque and output torque

The control of BLDC motor parameters can be obtained the voltage and the torque is directly proportional as by varying the motor input voltage. Table 3 is consists of shown in Figure 14. The relationship between voltage and the motor speed and torque with the change of the motor speed in rpm is shown in Figure 15 when the voltage voltage measurement. The relationship between changing increases the speed of the motor increases.

Table 3: Observations of BLDC motor under input torque 1N.m

\begin{tabular}{|c|c|c|}
\hline Voltage(v) & Torque(N-m) & Speed(rpm) \\
\hline 12 & 1.04 & 19 \\
\hline 15 & 1.053 & 71 \\
\hline 18 & 1.07 & 119 \\
\hline 20 & 1.089 & 151 \\
\hline 24 & 1.1 & 214 \\
\hline 26 & 1.135 & 241 \\
\hline 28 & 1.152 & 271 \\
\hline 30 & 1.17 & 307 \\
\hline 32 & 1.181 & 335 \\
\hline 34 & 1.193 & 365 \\
\hline 36 & 1.21 & 400 \\
\hline
\end{tabular}

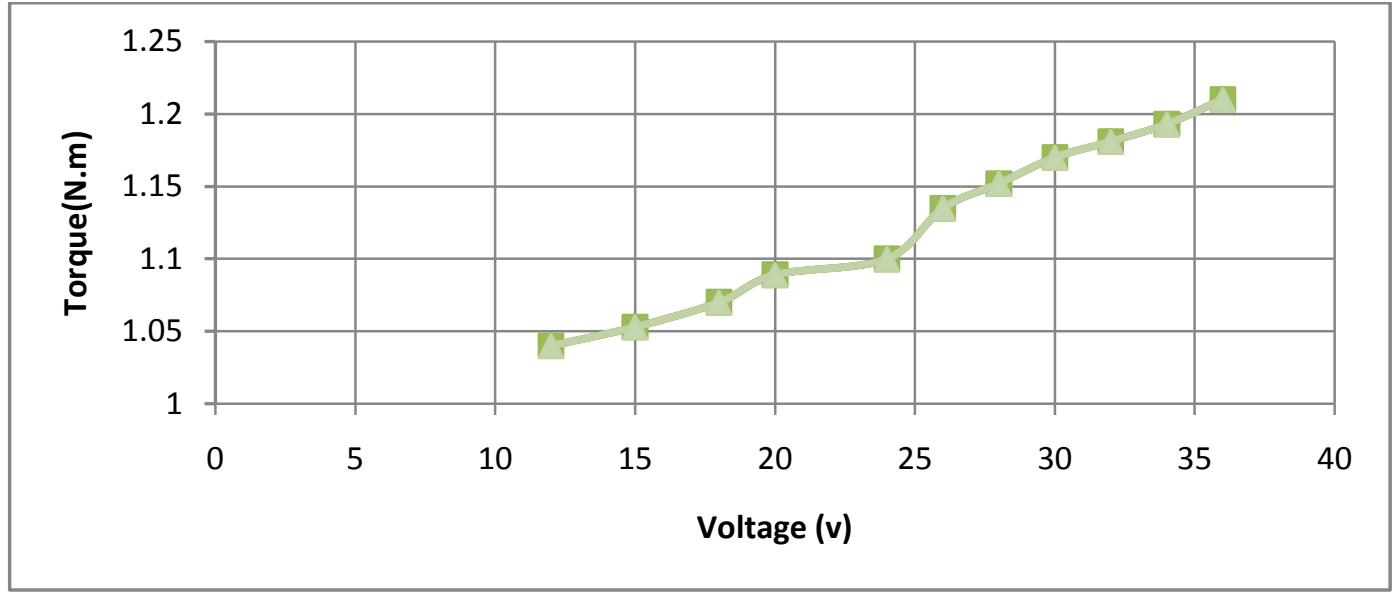

Figure 14: The relationship between voltage and torque 
IJIREEICE

International Journal of Innovative Research in Electrical, Electronics, Instrumentation and Control Engineering

ISO 3297:2007 Certified

Vol. 5, Issue 1, January 2017

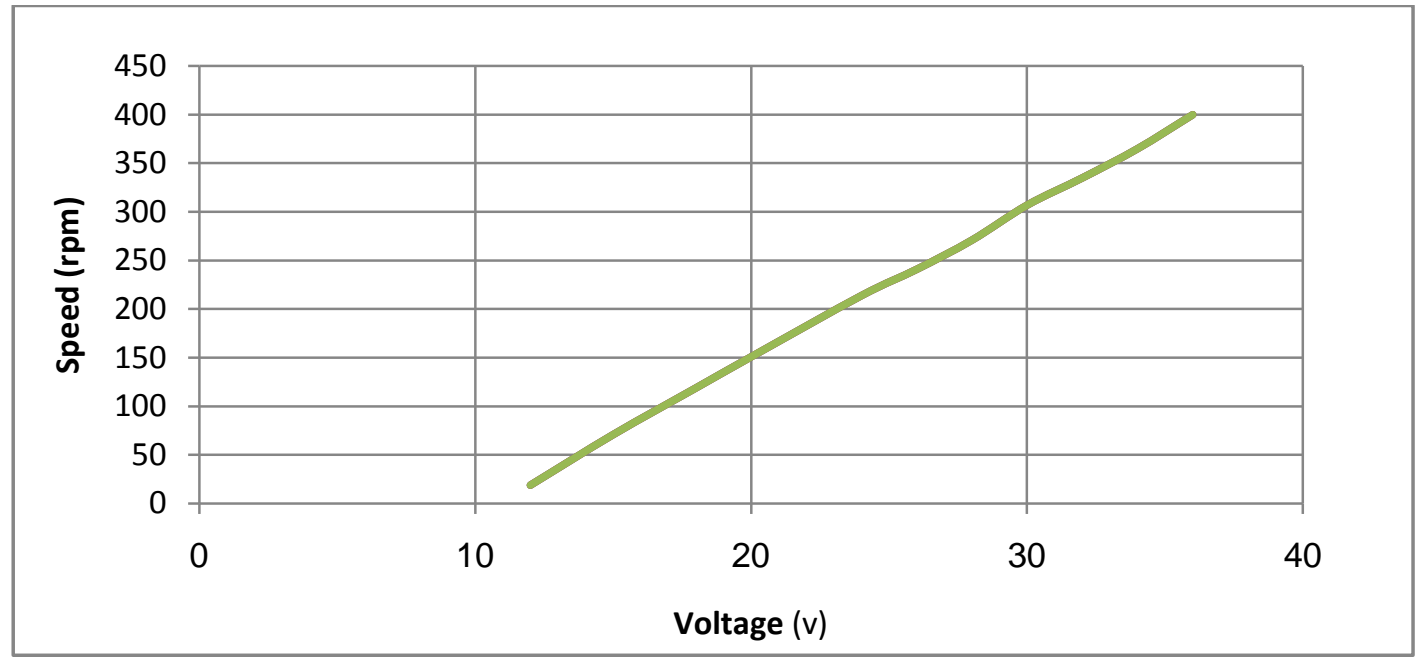

Figure 15: The relationship between voltage and Speed

\section{CONCLUSION}

This paper presents BLDC motor drive for electrical electric bicycle. The inverter is connected in the system to convert the $\mathrm{DC}$ voltage to $\mathrm{AC}$ voltage. The $\mathrm{AC}$ voltage is connected to brush less DC motor (BLDC). The signal generated by the pulse generator code is used to switch the inverter six transistors. The design of BLDC motor has been discussed in this paper. The produced simulation results shows that the generated code operate the motor successfully. The speed curve and the torque curve show the motor smooth operation. The speed torque waveform show the output response to the change of the input curve.

\section{REFERENCES}

[1] J. Zhao, Y. Yu , "Brushless DC Motor Fundamentals", mps The Future Of Analog IC Technology Application Note, AN047 Brushless DC Motor. 2011.

[2] Igor Jakubička; VladislavBača; Peter Fuchs; Peter Drahoš 'Implementing features of 32 bit DSP microprocessor for BLDC motorcontrol'2016 Cybernetics \& Informatics (K\&I) Year: 2016, Pages: 1 - 6

[3] Kun Xia; LirongShen; Bin Dong; Yanneng Zeng; Shuzhi Sam Ge 'Research of four-switch three-phase BLDC motor control scheme based on quasi Z-source converter' 2015 18th International Conference on Electrical Machines and Systems (ICEMS) Year: 2015, Pages: $1-6$

[4] M. A. A. Younis; N. A. Rahim; S. Mekhilef, 'High efficiency THIPWM three-phase inverter for grid connected system, 2010 IEEE Symposium on Industrial Electronics and Applications (ISIEA), Year: 2010, Pages: 88 - 93

[5] V. Sova; J. Chalupa; R. Grepl 'Fault tolerant BLDC motor control for hall sensors failure' 2015 21st International Conference on Automation and Computing (ICAC), Year: 2015, Pages: $1-6$

[6] Eka Firmansyah; F. DanangWijaya; W. P. RendyAditya; Ridwan Wicaksono 'Six-step commutation with round robin state machine to alleviate error in hall-effect-sensor reading for BLDC motor control' 2014 International Conference on Electrical Engineering and Computer Science (ICEECS) Year: 2014 Pages: 251 - 253

[7] Alexander Rowe; GourabSen Gupta; Serge Demidenko 'Instrumentation and control of a high power BLDC motor for small vehicle applications' 2012 IEEE International Instrumentation and Measurement Technology Conference Proceedings, Year: 2012, Pages: $559-564$
[8] M. S. Aspalli; FarhatMubeenMunshi; Savitri L. Medegar 'Speed control of BLDC motor with Four Switch Three Phase Inverter using Digital Signal Controller' 2015 International Conference on Power and Advanced Control Engineering (ICPACE) Year: 2015, Pages: 371 - 376 